\title{
"Futebol, paixão e política": construindo uma exposição temática em uma escola periférica de Ribeirão Preto/SP
}

\author{
"Football, Passion and Politics": Creating a Thematic Exhibition in a \\ Peripherical School in Ribeirão Preto/SP
}

\author{
Marcos Acácio Neli \\ Centro Social Marista Ir. Rui Leopoldo Depiné, Ribeirão Preto/Brasil \\ Doutor em Ciências Sociais, UNESP \\ E-mail: marcos_neli@yahoo.com.br \\ Victor de Vargas Giorgi \\ Centro Social Marista Ir. Rui Leopoldo Depiné, Ribeirão Preto/Brasil \\ Mestre em História, UFU
}

\begin{abstract}
RESUMO: O trabalho versará sobre o projeto "Futebol: paixão e política", realizado em um centro educacional ribeirão-pretano, levando em conta sua idealização, desenvolvimento e conclusão. Os docentes das áreas de Humanidades construíram, juntamente com os educandos, o projeto em questão, que trabalha diversas questões históricas, sociológicas e filosóficas através do desporto. Desta forma, refutamos a ideia de que o futebol é um mero entretenimento, entendendo-o como uma prática que nos ajuda a compreender diversas dinâmicas socioeconômicas e políticas sendo, portanto, um fecundo campo a ser trabalhado no espaço escolar, promovendo discussões em torno, por exemplo, da luta de classes, do preconceito racial e de gênero e do consumismo. 0 projeto procurou mobilizar ações e sensibilidades através da realização de debates, exibição de filmes/documentários e, principalmente, da montagem de um Museu Político do Futebol no colégio, com a exposição de produções dos estudantes. Este artigo representa um esforço em sintetizar os resultados alcançados pelo projeto e, também, em sistematizar as questões aqui desenvolvidas com o debate sociológico sobre a realidade do futebol contemporâneo.
\end{abstract}

PalaVRaS-ChaVe: Futebol; Política; Educação.

ABSTRACT: This paper will focus on the "Football: passion and politics" project, carried out in an educational center in Ribeirão Preto, state of São Paulo, Brazil, taking into account its idealization, development and conclusion. The professors of Humanities have built, alongside with the students, the project in question, which deals, through sport, with various historical, sociological, and philosophical issues. Thus, we refute the idea that football is mere entertainment, understanding it as a practice that helps us understand diverse socioeconomic and political dynamics, and is therefore a fruitful field to be used at the school space, promoting discussions around, for example, class struggle, racial and gender prejudice, consumerism. The project sought to mobilize actions and sensitivities by conducting debates, showing films/documentaries and, above all, setting up a Political Museum of Football in the school, with the exhibition of several student productions. This article represents an effort to synthesize the results achieved by the project, and also to systematize the issues brought by with the sociological debate about the reality of contemporary football.

KEYWoRDS: Football; Politics; Education. 


\section{INTRODUÇÃo}

[...] O futebol é mais do que um esporte, ou mesmo um modo de vida; abrange questões complexas que ultrapassam a arte do jogo. Envolve interesses reais - capazes de arruinar regimes políticos e deflagrar movimentos de libertação. Os clubes de futebol espelham classes sociais e ideologias políticas, e frequentemente inspiram uma devoção mais intensa que as religiões.

Frank Foer, Como o futebol explica o mundo.

0 presente artigo pretende apresentar o processo de idealização, desenvolvimento e conclusão do projeto "Futebol: paixão e política”, o qual está sendo implementado em uma unidade escolar de Ribeirão Preto, interior de São Paulo. Essa escola, de perfil filantrópico, possui como educandos jovens que habitam o Complexo Parque Ribeirão, que engloba uma série de bairros periféricos do município ribeirãopretano, tais como Jardim Progresso, Jardim Maria da Graça, Parque Ribeirão, Jardim Marchesi, Monte Carlo, entre outros. Os estudantes que participaram do projeto cursam o Ensino Médio, nos períodos matutino e noturno.

Nessa instituição, há o desenvolvimento de importantes trabalhos baseados na pedagogia de projetos e, desta forma, os educadores da área de Humanidades visaram a aproveitar o ano de Copa do Mundo, quando as atenções de parte significativa da população e, mais especificamente, do alunado, se voltam para o futebol, para desenvolver uma proposta de trabalho interdisciplinar, capaz de abarcar temas variados relacionados às disciplinas de História, Geografia, Sociologia e Filosofia que pudessem suscitar reflexões de como o futebol extrapola a simples atividade desportiva.

Dessa forma, este artigo pretende analisar as ações desenvolvidas durante a realização deste projeto trazendo luz para as análises realizadas pelos educandos a partir do tema do futebol.

\section{JUSTIFICATIVAS E ANÁLISE DO PROBLEMA}

Acompanhando o fenômeno da globalização, verificamos, nas últimas décadas, uma mercantilização do futebol como um produto da indústria do entretenimento. 
As análises sobre a contemporaneidade e as complexas redes de relações entre a produção cultural, público e agentes que atuam diretamente nestas, seja de modo a produzi-las e apoiá-las, como também como atores dessas produções foram analisadas de forma bastante profundas por Guy Debord em seu célebre livro $A$ sociedade do espetáculo, de 1967.

O espetáculo, compreendido na sua totalidade, é simultaneamente o resultado e o projeto de modo de produção existente. Ele não é um complemento ao mundo real, um adereço decorativo. É o coração da irrealidade, da sociedade real. Sob todas as suas formas particulares de informação ou propaganda, publicidade ou consumo direto do entretenimento, o espetáculo constitui o modelo presente da vida socialmente dominante. Ele é a afirmação onipresente da escolha já feita na produção e no seu corolário - o consumo. A forma e o conteúdo do espetáculo são a justificação total das condições e dos fins do sistema existente. 0 espetáculo é também a presença permanente desta justificação enquanto ocupação principal do tempo vivido fora da produção moderna. ${ }^{1}$

A partir do exposto podemos compreender que a indústria cultural moderna ${ }^{2}$ cria o espetáculo e também seu consumo, uma vez que ambos são um produto que surge a partir de demandas técnicas e financeiras do mercado capitalista de produção. Os atores envolvidos neste percurso são, muitas vezes, produtos criados e difundidos através de estratégias de marketing e alçados ao estrelismo midiático que pode ser, em muitos casos, instantâneos e passageiros.

Essa análise à primeira vista poderia relegar o futebol a uma categoria qualquer de entretenimento e de passatempo, contudo, uma análise mais profunda e próxima pode trazer elementos de grande apuro teórico para a compreensão de questões sociais, políticas e econômicas. O futebol como palco para o olhar multidimensional e das relações de poder que lhes são inerentes é o ponto central do projeto que foi idealizado e desenvolvido junto aos educandos dessa unidade escolar. Perceber as relações além da realidade aparente e jogar luz nas imbricações que, à primeira vista gestam apenas interpretações fetichizadas, mas que escondem formas profundas de compreender a realidade em que estão inseridos tanto atores

\footnotetext{
${ }^{1}$ DEBORD. A sociedade do espetáculo, p. 15.

2 Termo cunhado por Adorno e Horkheimer autores proeminentes do grupo que ficou conhecido como Escola de Frankfurt.
} 
quanto espectadores são o foco deste projeto. As relações de poder e submissão desempenhadas e tomadas pela indústria cultural sobre seus produtos não podem ser analisadas como passos certeiros e sem desvios. Elas trazem a dialética daquilo que lhe é mais peculiar a produção de um espetáculo feito por seres humanos para seres humanos. E essas relações, como poderemos observar, extrapolam o simples entretenimento, trazem elementos de contestação e de negação do futebol como mera atividade pueril de diversão e alienação. 0 futebol traz consigo a capacidade de despertar paixões cegas, mas também, e na mesma medida, a contestação política e econômica daquilo que lhe criou.

A evolução dos meios de transporte fortaleceu campeonatos de âmbito continental e mundial. Não obstante, como destaca o estudioso Edson Hirata (2014), em seu artigo "Futebol e globalização: perspectivas teóricas", a velocidade com que as informações ligadas ao campo esportivo são disseminadas igualmente potencializaram a espetacularização do futebol. Tecnologias como a internet e sistemas de mensagens instantâneas via celular, além da criação de canais de televisão por assinatura e o fortalecimento das grandes marcas patrocinadoras, promoveram uma aceleração e inovação da maneira como os esportes em geral e, mais especificamente, o futebol chega aos torcedores/consumidores, tornando-se um fecundo mecanismo gerador de rendimentos. As cifras ligadas às transações de grandes estrelas do futebol chegaram a patamares elevadíssimos. Nesse contexto, debates entre aqueles que são favoráveis às novas tendências do futebol moderno e os que rememoram saudosistamente o "futebol raiz" são frequentes. Em sua obra Futebol ao sol e à sombra o célebre escritor Eduardo Galeano (1995) tece uma contundente crítica à capitalização do esporte em questão, enfatizando que:

[...] A história do futebol é uma triste viagem do prazer ao dever. A medida que o esporte se fez indústria, foi-se desterrando a beleza que nasce da alegria de jogar porque sim. Neste mundo de final de século, o futebol profissional condena o que é inútil, e é inútil o que não é rentável. [...] 0 jogo se transformou em espetáculo, com poucos protagonistas e muitos espectadores, futebol para olhar, e o espetáculo se transformou num dos mais lucrativos do mundo, que não é organizado para ser jogado, mas para impedir que se jogue. A tecnocracia do esporte profissional foi impondo um futebol de pura velocidade e muita força, que renuncia à alegria, atrofia a fantasia e proíbe a ousadia. [...] por sorte ainda aparece nos campos, embora muito de vez em quando, algum atrevido que sai do 
roteiro e comete o disparate de driblar o time adversário inteirinho, além do juiz e do público das arquibancadas, pelo puro prazer do corpo que se lança na proibida aventura da liberdade. ${ }^{3}$

O futebol é muitas vezes encarado como um simples entretenimento em que o destaque fica, muitas vezes, com os salários milionários de alguns jogadores ou, ainda, as paixões da torcida que são levadas ao extremo. Entretanto, ao analisarmos as relações humanas travadas em torno deste jogo, percebemos que há sentidos que ultrapassam o seu caráter esportivo. Como exemplo, no Brasil, especialmente nas décadas de 1960 a 1980, alguns jogadores tiveram papel de destaque na luta pela redemocratização do país. Os jogadores do Botafogo, na década de 1960, e do Corinthians, na década de 1980, levaram de forma vigorosa a luta pela democracia e a reflexão sobre o papel do futebol em um contexto de exceção. Desta forma, os limites comumente aferidos ao esporte são, em muitos casos, ilusórios, já que relações sociais, econômicas, políticas e culturais fazem parte do desporto.

É possível afirmar que o futebol, quando tornado objeto de estudos, fomenta uma série de debates vinculados a questões históricas, sociológicas, filosóficas, entre outras. Das torcidas organizadas à chamada "democracia corintiana"; da apropriação do futebol por meio do governo ditatorial brasileiro ao surgimento, na contemporaneidade, de torcidas organizadas antifascistas; da visão do futebol enquanto elemento cultural à perspectiva do esporte como mecanismo de alienação e parte integrante do "pão e circo". Tais temas, associados a outros mais, uma vez trabalhados no espaço escolar, possibilitam uma maior compreensão acerca de determinadas dinâmicas socioeconômicas e políticas observadas em nosso país, tanto no passado como no presente. 0 projeto "Futebol: paixão e política" tem por escopo principal, portanto, a análise dessas relações que ultrapassam o simples entretenimento, de modo a resgatar os processos de identidade, cultura e política que permeiam e ultrapassam as relações do mundo do futebol. Nesse sentido, fazemos nossas as palavras de Gustavo Hofman (2014), autor de Quando o futebol não é apenas um jogo:

\footnotetext{
${ }^{3}$ GALEANO. Futebol ao sol e à sombra, p. 13.
} 
[...] O futebol, através de uma equipe, pode representar uma pátria sem terra; mostrar ao mundo o sofrimento de um povo; explicar com outros olhos uma guerra; traduzir a indignação de uma torcida; exemplificar paixões; traduzir geopolíticas; trazer a economia mundial para uma roda de bar; ou simplesmente contar uma história curiosa. (...) 0 mundo do futebol não é feito apenas de Liga dos Campeões, salários milionários e histórias cheias de glamour e fama. Ele é, acima de tudo, composto por histórias de superação, curiosidades e fatos históricos que mostram como o jogo, muitas vezes, é apenas um detalhe. Em diversos casos, e em determinados momentos, o detalhe mais importante da vida. ${ }^{4}$

Portanto, diante de um cenário político conturbado, marcado pela discussão e aprovação de emendas retrocedentes por parte do Congresso, pelo aprofundamento das desigualdades socioeconômicas entre os brasileiros, pela usurpação de direitos historicamente conquistados pelo povo e pelos discursos extremistas e de ódio, entre outros, acreditamos, no momento de conceber o projeto, que o futebol, uma das maiores paixões do brasileiro e símbolo identitário nacional, poderia servir de "gatilho" para a promoção de múltiplas discussões.

Dentre os principais temas abordados em nossos debates, destacaram-se: as múltiplas versões sobre a origem do futebol no Brasil; o esporte e a luta de classes; os preconceitos racial e de gênero no futebol; o fenômeno das torcidas organizadas; o esporte enquanto engendrador de manifestações políticas; a forma como que o futebol foi, e permanece sendo, apropriado pelos políticos para a autopromoção de seus governos, entre outros.

Levando em consideração a pedagogia de projetos, adotada pelo Centro Educacional, procuramos desenvolver nosso trabalho explorando as características essenciais delineadas por Fernando Hernandéz (1998) para essa modalidade de ensino-aprendizagem, as quais se apresentam na forma de "visões". Em primeiro lugar, de acordo com o estudioso em questão, uma visão política, vinculada à noção de democracia radical, deve ser fomentada pelos educadores junto aos educandos no momento do desenvolvimento de um projeto, para que estes tornem-se aptos a tomar decisões e assumir responsabilidades sobre aquilo que concerne a suas vidas.

Por sua vez, uma visão educativa precisa necessariamente aflorar entre os membros da comunidade escolar, para que esta desenvolva uma aprendizagem

\footnotetext{
${ }^{4}$ HOFMAN. Quando o futebol não é apenas um jogo, p. 11.
} 
aberta, pautada na partilha de conhecimentos entre todos e onde a investigação sobre o real adquire um papel imprescindível. Ademais, a pedagogia em questão deve estar circunscrita a uma visão curricular, a qual se projeta em um currículo integrado de caráter transdisciplinar, e que seja reflexo de um diálogo permanente com a sociedade e com as transformações operadas em seu interior.

Por fim, Hernandéz salienta a importância do despertar de uma visão de conhecimento, vinculada ao desejo de aprender com todos os agentes do processo educativo, que incida sobre a complexidade dos saberes, e que desperte a busca pelo aprendizado dentro e fora do espaço escolar. Ao edificarmos o projeto "Futebol: paixão e política", buscamos potencializar a formação dos estudantes em suas múltiplas dimensões, concebendo a existência de não uma, mas diversas inteligências (cognitiva e socioemocional, por exemplo), as quais precisam ser estimuladas para que tais jovens se desenvolvam plenamente enquanto agentes transformadores.

\section{DESENVOLVIMENTO DO PROJETO}

Levando em consideração a importância da escuta e da partilha de saberes, compreendemos que a primeira etapa do projeto deveria ser pautada na apresentação de nossa proposta aos educandos, para que estes pudessem se manifestar, trazendo informações e emitindo opiniões. De modo geral, pudemos aferir que os estudantes se mostraram animados com nossas ideias e, desta forma, coletivamente "desenhamos" as etapas do projeto que seriam percorridas nos meses subsequentes, criando um cronograma de atividades e delineando os temas que seriam trabalhados em sala de aula.

\section{a. EXIBIÇÃO DE DOCUMENTÁRIOS E LEITURA DE ARTIGOS, EM GRUPOS}

As turmas do Primeiro Ano do Ensino Médio (A, B e C) optaram por trabalhar os temas "O futebol e a identidade nacional", "O futebol em Ribeirão Preto" e "As torcidas organizadas no Brasil". Diante disso, inicialmente, os docentes exibiram o documentário Torcidas Organizadas, criado pela Fundação Getúlio Vargas em parceria com o Museu do Futebol, que analisa tais grupos sob variados prismas, não 
se limitando a uma imagem (muito difundida) do torcedor-vândalo. Em um segundo momento, os alunos foram divididos em grupos e leram trechos do artigo "Brasil: futebol e identidade popular", do pesquisador Luiz Carlos Ribeiro, o qual traça um percurso histórico do futebol brasileiro ao longo do século XX, demonstrando a íntima relação do desporto com as grandes massas em nosso país. Em um terceiro momento, os estudantes foram até o laboratório de informática, onde pesquisaram as origens e os principais acontecimentos ligados aos principais times de Ribeirão Preto, Botafogo e Comercial.

Por sua vez, as turmas do Segundo (A, B e C) e do Terceiro Ano (A, B, C e D) do Ensino Médio decidiram explorar os assuntos "Os primórdios do futebol no Brasil", "O futebol e a luta de classes", "Futebol e preconceito", "Futebol e manifestação política" e "O esporte no contexto da ditadura civil-militar brasileira". Deste modo, os professores optaram por exibir o documentário Adeus, geral, que explora o contemporâneo fenômeno de elitização do futebol no mundo e, mais especificamente, no Brasil, através da construção de arenas modernas, das estratégias de cerceamento adotadas contra as torcidas organizadas e da "destruição" das gerais nos estádios, áreas outrora destinadas às camadas populares e com preços mais acessíveis.

Posteriormente, os alunos, em sala de aula, foram divididos em grupos para a leitura e discussão de uma série de matérias jornalísticas e artigos com temáticas variadas. Dentre tais fontes, podemos destacar Primórdios do futebol no Brasil, de Cláudio Fernandes; O futebol e as lutas do povo, de Lucas Prestes; Evento esportivo não é lugar de manifestação política, de Tiago Leifert; $O$ bom senso e as lutas de classes no Brasil, de Ricardo Flaitt; A seleção que despreza sua gente, de Breiller Pires e Opinião: o futebol feminino e o preconceito social, de Chiara Ribeiro. Enquanto liam e discutiam os assuntos tratados pelos textos, os docentes, em pares, faziam um rodízio, sentandose brevemente para ouvir, opinar, esclarecer dúvidas, entre outros.

\section{b. REAlizaÇão dos Debates EM SALA DE AULA}

A segunda etapa do projeto consistiu na realização de debates com os educandos em sala de aula, os quais foram mediados pelos educadores. Em roda, inicialmente 
pedimos aos alunos que explicassem brevemente os temas centrais dos artigos previamente lidos, ressaltando os principais pontos discutidos por eles quando formaram os grupos. De acordo com o que os educandos destacavam, levantávamos hipóteses, aprofundávamos assuntos e apresentávamos novas perspectivas, de modo a incitar a discussão. Essa atividade se mostrou extremamente profícua. Pudemos notar que diversos alunos com perfis mais introspectivos se mostraram mais abertos ao diálogo, expondo suas opiniões e tendo o seu interesse despertado. Da mesma forma, aferimos grande capacidade, por parte de determinados educandos, de realizar análises acerca da sociedade a partir do futebol.

Por exemplo, ao abordarmos a forma com que o governo brasileiro se apropriou da conquista do mundial de 1970, no contexto da Ditadura Civil-Militar, na tentativa de enaltecer os valores patrióticos e o culto à nação, alguns alunos ressaltaram a estratégia adotada pelo governante de mascarar escândalos de corrupção investindo na organização das edições da Copa do Mundo de 2014 e dos Jogos Olímpicos de 2016 no Brasil. Da mesma forma, ao explicitarmos o fato de que diversos clubes de futebol negavam a participação de atletas negros nos primórdios do esporte no país, os estudantes facilmente notaram a permanência do preconceito racial, destacando casos de racismo no esporte e presenciados por eles no dia a dia, o que, por sua vez, abriu caminho para que falássemos do preconceito de modo mais amplo, explorando questões de gênero e classe. A discrepância dos salários da jogadora Marta e de Neymar e a falta de visibilidade do futebol feminino fomentaram uma discussão mais ampla, que englobou o machismo, a atuação do movimento feminista no Brasil e os papéis socialmente impostos às mulheres.

Outro ponto bastante discutido foi o caráter político das práticas e eventos esportivos. Realizando um contraponto à percepção de Tiago Leifert em relação aos eventos desportivos, que para ele são momentos de lazer, onde o público/telespectador pode relaxar, deixando de pensar nos problemas que afligem o país, os educandos notaram que as torcidas trazem, com frequência, questões debatidas na sociedade para dentro do campo, marcando posições contrárias ao governo, à espetacularização e mercantilização do futebol, às gestões dos dirigentes dos clubes etc., o que os levou a pensar se, de fato, existe algum espaço social que não seja essencialmente político. Quanto ao papel 
desempenhado pelas torcidas organizadas, embora condutas violentas tenham ganhado destaque a longo dos debates, alguns estudantes destacaram conhecer ou mesmo fazer parte destes grupos, destacando o caráter festivo e incentivador de suas práticas.

Ao concluirmos esta etapa, avaliamos positivamente o resultado das discussões, levando em consideração a participação, o empenho em realizar pesquisas prévias e trazer dados relacionados aos temas e a compreensão geral, por parte dos educandos, da perspectiva de se estudar fenômenos sociais por intermédio do futebol, relacionando-os às suas próprias vivências enquanto agentes sociais.

\section{c. PALESTRA COM O EX-JOGADOR PROFISSIONAL NILTON PELLEGRINI}

Com o intuito de trazer uma perspectiva de quem esteve nos campos de futebol, nós, docentes da área de Humanidades, convidamos ao Centro Educacional o ex-jogador profissional Nilton Pellegrini, que atuou como goleiro nas décadas de 1970 e 1980 em diversos clubes brasileiros, tais como o Botafogo-SP, Comercial, Santos (tendo jogado no mesmo elenco de Sócrates), Apucarana, entre outros. Diversos foram os temas abordados pelo palestrante, tais como: as dificuldades experimentadas pelos jogadores de times de menor expressão; as abissais diferenciações salariais dos atletas da Série A frente aos jogadores das demais divisões dos campeonatos nacionais; as transformações ocorridas no futebol do tempo em que atuou frente à contemporaneidade, e a relação dos jogadores com as torcidas, com os técnicos e com os dirigentes. Atualmente professor de Educação Física, Pellegrini enfatizou em inúmeros momentos a importância da educação para a formação dos jovens, independentemente da carreira que forem seguir, rompendo, deste modo, com a visão de que o futebol garante uma plena estabilidade financeira aos jogadores. Pudemos aferir, em termos gerais, um envolvimento significativo dos educandos no decorrer da palestra, o que pôde ser comprovado a partir da vultosa quantidade de perguntas por eles realizadas e destinadas ao ex-jogador. 


\section{d. CONFECÇÃo de CARTAZES}

A quarta etapa do projeto se deu através da produção, por parte dos educandos, de uma série de cartazes relacionados aos temas trabalhados no decorrer das atividades precedentes, isto é, "Futebol e política", "Futebol e preconceito", "Torcidas Organizadas", "Futebol e luta de classes", "O esporte no contexto da Ditadura Civil-Militar", "Futebol e identidade nacional”; "Os primórdios do futebol no Brasil" e "Futebol em Ribeirão Preto". Essa atividade, tal como os debates, foi delineada para ser um instrumental avaliativo, à medida em que exigiu dos estudantes um esforço de rememoração daquilo que fora debatido, de pesquisa de novos elementos a serem apreendidos e introduzidos nos trabalhos e, por fim, de síntese e "transcriação" dos aspectos estudados na forma de tópicos esquemáticos, desenhos e textos de cunho próprio.

\section{e. Montagem do Museu Político do Futebol}

Por fim, em setembro ocorreu a culminância do projeto com a montagem do Museu Político de Futebol no Centro Educacional. 0 museu foi concebido de forma a proporcionar diferentes experiências aos visitantes. Em uma das laterais da sala, foram afixados os cartazes produzidos pelos educandos ao longo do projeto. Nesta parte da sala, igualmente foram afixados cartazes que aludem às principais pautas colocadas pela sociedade na contemporaneidade, em uma releitura das demandas trazidas pelas torcidas brasileiras no contexto da redemocratização.

Em outra parede, foram expostas produções dos educandos sobre a Taça Libertadores da América, principal competição futebolística sul-americana, cujo nome remete a Símon Bolívar e José de San Martín, responsáveis por liderar tropas que lutaram pela independência de boa parte dos atuais países da América do Sul. Ademais, fizemos uma singela homenagem à equipe da Chapecoense, vitimada por um acidente aéreo na Colômbia, quando viajava para disputar a final da Copa SulAmericana de 2016, e uma referência ao clássico municipal “Come-Fogo", disputado pelas equipes Botafogo/SP e Comercial de Ribeirão Preto. Dentre outros artigos expostos, merecem destaque álbuns de figurinhas de edições da Copa do Mundo; 
"mini craques"; camisas de equipes nacionais e internacionais, além daquelas utilizadas pelos educandos em campeonatos por eles disputados; mapas táteis confeccionados pelos educandos, entre outros.

Nos momentos de visitação, contamos com o apoio de educandos que atuaram como monitores, os quais relataram terem gostado bastante da experiência. Para as turmas que adentravam o museu, os educadores leram a crônica "Futebol de rua", de Luís Fernando Veríssimo, que procura estipular as possíveis regras de uma das brincadeiras mais praticadas pelas crianças e adolescentes, e foram exibidos dois vídeos, o primeiro sobre os cem gols mais belos da história, enquanto que o segundo foi o curta-metragem Barbosa, estrelado por Antônio Fagundes, que aborda o Maracanazo, quando a seleção brasileira foi derrotada por 2 a 1 pelos uruguaios na final do Mundial de 1950, no Rio de Janeiro, e a tentativa frustrada do personagem principal de reverter esse episódio por meio de uma viagem ao tempo.

A exposição ocorreu ao longo de uma semana, sendo que os visitantes foram os próprios educandos do Centro Educacional. Para além das turmas do Ensino Médio, os estudantes do Ensino Fundamental II e de um programa de convivência ofertado no contra turno escolar puderam conferir a apresentação, tendo apresentado a nós um retorno bastante favorável da experiência.

\section{CONSIDERAÇões FinAIS}

Ao término do projeto "Futebol: paixão e política", avaliamos, de modo geral, os resultados apresentados de forma positiva. Parte significativa dos educandos se identificaram com a proposta de trabalho e participaram ativamente de suas diversas etapas. Para nós foi bastante significativo notar o envolvimento de alguns estudantes que no "dia a dia" não adotam uma postura protagonista em sala de aula, mas que no projeto buscaram assumir um papel de construtores do próprio saber. Não obstante, aferimos certo destaque de determinadas educandas, notadamente quando trabalhamos o tema "futebol e gênero", as quais ganharam voz para expor suas opiniões sobre questões como a discrepância salarial entre homens e mulheres e a representação machista da mulher enquanto "sexo frágil'. 
Sob outro ângulo, o principal percalço por nós observado foi a dificuldade de compreensão, por parte de determinados educandos, de conceitos-chave fundamentais para uma plena apreensão das questões trazidas à baila nos debates, como, por exemplo, "classe", "resistência", "gênero", "Estado" e "ideologia”. Isso se deve, dentre outros fatores, ao fato de que muitos desses estudantes não tiveram uma sólida base formativa, haja vista terem vindo de escolas públicas locais, espaços que enfrentam inúmeros problemas, que vão da precária estrutura física à falta de educadores. Contudo, mesmos esses educandos conseguiram construir conhecimentos, opinando nos debates, por exemplo, de acordo com suas próprias experiências.

\section{REFERÊNCIAS}

ALTMAN, Gustavo et. al. Adeus, geral. 2016. Disponível em: https://bit.ly/2E7fXyP. Acesso em: 27 nov. 2019.

DEBORD, Guy. A sociedade do espetáculo. Coletivo Periferia (eBook), 2003.

FERNANDES, Cláudio. Primórdios do futebol no Brasil. In: Brasil Escola. Disponível em: https://bit.ly/2PcX8AT. Acesso em 27 nov. 2019.

FGV / MUSEU DO FUTEBOL. Territórios do Torcer. 2015. Edição: CPDOC. Disponível em: https://bit.ly/36sOiEy. Acesso em: 27 nov. 2019.

FLAITT, Ricardo. O Bom Senso e as lutas de classe no futebol. In: Lance! Disponível em: https://bit.ly/35ejKGu. Acesso em: 27 nov. 2019.

FOER, Franklin. Como o futebol explica o mundo. Jorge Zahar Editor, 2005.

GALEANO, Eduardo. Futebol ao sol e à sombra. Porto Alegre: L\&PM, 1995. HERNANDÉZ, Fernando. Transgressão e mudança na educação. Porto Alegre: Autmed, 1998.

HIRATA, Edson. Futebol e globalização: perspectivas teóricas. EFDeportes.com, Revista Digital. Buenos Aires, Ano 19, n. 196, set. 2014.

HOFMAN, Gustavo. Quando o futebol não é apenas um jogo. Rio de Janeiro: Via Escrita, 2014. 
LEIFERT, Tiago. Evento esportivo não é lugar de manifestação política. In: GQ/Globo. Disponível em: https://glo.bo/2LKEw9g. Acesso em: 27 nov. 2019.

PIRES, Breiller. A seleção que despreza sua gente. In: El País. Disponível em: https://bit.ly/2RJ5t0S. Acesso em: 27 nov. 2019.

PRESTES, Lucas. O futebol e as lutas do povo. In: UJC. Disponível em: https://ujc.org.br/o-futebol-e-a-luta-do-povo/. Acesso em: 27 nov. 2019.

RIBEIRO, Chiara. Opinião: o futebol feminino e o preconceito racial. In: Torcedores. Disponível em: https://bit.ly/2YED6C9. Acesso em: 27 nov. 2019.

RIBEIRO, Luiz Carlos. Brasil: futebol e identidade. In: EFDeportes.com. Revista Digital - Buenos Aires - Ano 8 - $\mathrm{N}^{\circ} 56$ - janeiro de 2003. Disponível em: https://www.efdeportes.com/efd56/futebol.htm. Acesso em: 27 nov. 2019.

Recebido para publicação em: 12 mar. 2019.

Aprovado em: 25 nov. 2019. 